tageous in making equipment available should trouble develop in one source. It also enables a continuous check to be maintained of the difference between the frequency of the two sources, and thus gives prompt indication of any incipient trouble.

A basic frequency of $100 \mathrm{kc}$. is generated by an oscillator circuit in an upper panel, and immediately below this is a $100 \mathrm{kc}$. amplifier. Below this again are three panels, producing submultiple frequencies of $10 \mathrm{kc}$., of $1 \mathrm{kc}$. and of 100 cycles. Another bay is provided for frequency checking which, besides providing for comparing the two frequencies with each other, also permits either to be checked against a standard $5 \mathrm{mc}$. frequency sent out over Station $W W V$ by the National Bureau of Standards in Washington. A further bay provides independent power supplies for each of the three units. Power is taken at 117 volts and 60 cycles from the commercial supply, and from it four units produce regulated D.c. for plate supply, while a fifth unit supplies regulated A.c. heater voltage. There is one D.c. power supply for each of three bays, while a fourth serves as a spare, and may be connected in place of any of the other three by running cords between them.

\section{Preservative for Telephone Poles}

To be effective in prolonging the life of wood in contact with the ground, water-soluble materials must undergo a change after injection which will render them insoluble while retaining their preservative value. An article by C. M. Hill (Bell Lab. $R e c ., 21$, No. 3 ; November 1942) discusses a new preservative, now known as 'greensalt'. The composition mostly used contains potassium dichromate, copper sulphate and arsenic acid in solution. Variants include sodium dichromate as a substitute for the potassium salt, and also mixtures of chromic acid, copper carbonate and arsenic acid. These preservatives, particularly the first one, have been given extensive laboratory tests to determine their preservative value in wood and their permanence.

Small blocks of southern pine sapwood were impregnated with solutions of graded concentration and afterwards subjected to the attack of wooddestroying fungi under controlled laboratory conditions. Blocks similarly impregnated were subjected to exhaustive leaching, and the leach waters were analysed for copper, chromium and ursenic; the leached blocks were then exposed to fungus attack. The tests showed that greensalt became almost completely insoluble within a short time after injection, and both leached and unleached blocks satisfactorily withstood fungus attacks. Outdoor exposure tests on southern pine saplings 1 in. in diameter and posts $4-5$ in. in diameter treated with greensalt were begun in 1934 under conditions very favourable to rapid destruction of wood in contact with the ground. The seven-year record of exposed specimens treated with $\frac{1}{2} \mathrm{lb}$. and $\mathrm{I} \mathrm{lb}$. of greensalt preservative per cu. $\mathrm{ft}$. of wood is excellent in comparison with simultaneous similar tests of preservatives of established standing, including creosote.

\section{Wood Pigeon Investigation}

THE report of the Edward Grey Institute's wood pigeon investigation in 1942, recently issued in the Wood Pigeon Bulletin No. 4, makes interesting reading in view of the concern over this bird's damage to war-time crops, for 1,734 nests were recorded on habitat cards and 32,276 birds recorded in field counts in the first six months of the year. Comparison is made between 458 nests recorded from northern England and 1,084 from the south, and the seasonal distribution of the percentage of nests respectively was, after May 31,91 and 86 ; after June 30,67 and 68 ; after July 31,37 and 45 ; after August 31, 14 and 19. Two thirds of the nests were found after June 30, confirming earlier indications of the species' late breeding habits. Of the field counts, only a quarter were on clover and just over a quarter on corn, and over the whole country, on the average, the greatest number of wood pigeons was seen in January and February, after which there was a steady decline, the June figures being only one fifth of the February peak. More birds were recorded per observer in the south than in the north, but the maximum was in the Midlands. Regarding the wild food of these birds, phenologists of the Royal Meteorological Society record that, partly owing to the absence of late frosts in 1942, both oaks and beeches fruited more plentifully than in 1941 ; oaks fruited best in the north and west, and beech fared worst in the south. A plague of caterpillars in May, it is noted, may cause wood pigeons some six months later to turn their attention to cultivated crops.

\section{Staffordshire Ecology}

THE 1942 report issued by the East Staffordshire Branch of the British Empire Naturalists' Association contains recorders' reports on the faunal and floral survey conducted during the year at four selected localities-Sutton Park, Hopwas Woods (Tamworth), Randan Woods, and Minworth Sewage Works. In the Randan Woods lists, F. Fincher includes the badger, winter siskins, the nightingale and nuthatch, a male golden oriole on May 26, but the nightjar has disappeared as a nesting species. Butterflies are increasing, notably wall brown, comma, the pearlbordered fritillaries, speckled wood, large skipper, while rare records in 1942 included the wood white and white-letter hairstreak. Seven species of Bombus (Hymenoptera), four of Vespa and three of ants were noted. Of the flora, adder's tongue ferm and twayblade have increased. N. Grove and M. H. Asterley record as visitors at Minworth Sewage Works many duck and waders, the reed warbler nesting, 119 house-martin nests under the eaves of a power house the roof of which was burnt out during the previous winter. Major A. de Hamel's lists for Tamworth note an increase of jackdaws, jays, spotted flycatchers and swifts, and a decrease of swallows, house martins, and wood pigeons. The willow tit is included. Grasshoppers, dragonflies, beetles and fungi are also listed in the reports of the recorders, and there are notes from some other localities, including white helleborine at King's Norton.

\section{Mythology of Cancer Research}

UNDER this heading, the Lancet of December 26 has an article by Prof. E. L. Kennaway, who states that the literature of cancer research contains frequent references to an alleged piece of evidence for the carcinogenic action of arsenic recorded by Dr. J. A. Paris, F.R.S., senior physician to West- 